\title{
Research on Interface bond strength and bond-slip constitutive models for rectangular CFST columns
}

\author{
XIUSHU QU1, a *,QI LIU2,b \\ ${ }^{1}$ School of Civil and Transportation Engineering, Beijing University of Civil Engineering and \\ Architecture,Beijing, 100044, P.R. China \\ ${ }^{2}$ School of Civil and Transportation Engineering, Beijing University of Civil Engineering and \\ Architecture,Beijing, 100044, P.R. China \\ aemail:quxiushu@126.com \\ bemail:2571116069@qq.com
}

\begin{abstract}
Keywords: rectangular concrete-filled cold-formed steel tubular; interface bond strength; T-S constitutive models

Abstract. More recent studies have suggested that parameters such as cross-section type, cross-sectional dimensions, interface length, concrete compressive strength, slenderness ratio, steel strength, roughness of interface, concrete casting style, and concrete curing conditions potentially have some influence on the value of the bond strength. In this paper, a brief review of previous research and literature that are pertinent to the present study of the interface bond strength and $\tau-S$ constitutive models are presented first. According to the previous laboratory testing results, three equations are designed to calculated are average elastic limit bond strength, average ultimate bond strength and average post-peak residual bond strength, respectively. Moreover, a new simplified four-part model has been proposed to describe the $\tau-S$ response.
\end{abstract}

\section{Introduction}

The steel-concrete interface bond stress is the force being on the interface between the steel tube and the concrete core. It is the guarantee to assure the concrete and steel tube to work together. In the beam-column joint area, shearing force from the beam translates to the steel tube of the column through the beam-to-column connection. Then, it is gradually translated into the core concrete through the steel-concrete interface bond stress. The value of interface band strength can influence the load transfer to a certain extent and it is the key point for the individual differences of different calculation theories. Parameters such as cross-section type, cross-sectional dimensions, interface length, concrete compressive strength, slenderness ratio, steel strength, roughness of interface, concrete casting style, and concrete curing conditions potentially have some influence on the value of the bond strength [1-6]. Previous research on the bond strength versus slip $(\tau-S)$ constitutive model is relatively small.

\section{Previous Laboratory Testing for Interface Bond Strength}

The earliest research on the interface bond strength of rectangular CFST columns was carried out by Virdi and Dowling in 1975 [1]. A push-out test programme applied to 88 circular CFT columns were conducted to investigate the value and the composition of the bond strength. It was found that the bond strength did not appear to be greatly influenced by the variation in the concrete cube strength. In 1991, push-out tests have been carried out on 36 CFST stub columns by Shakir-Khalil [7]. The tests showed that the push-out load is a variation upon or function of the shape of the steel hollow section, as well as also a variation or function of the type of shear connectors and the way in which the load is applied to the steel section.In 1993, a further experimental study on the interface condition as applied to the interface bond strength was investigated by Shakir-Khalil [6]. Six out of twelve of square CFST columns and six out of twelve circular columns were tested by means of oiling the steel-concrete interface. The results of the tests indicated that oiling the steel-concrete interface resulted in its halving the bond strength. In 1997, an experimental investigation of 20 circular CFST columns was performed by Cameron to examine the bond stress capacity and the test results were analyzed in 1999 [8]. The concrete shrinkage, which depends upon the characteristics 
of the concrete, the diameter of the tube and the surface condition of the inside of the tube were regarded as the most detrimental contributing parameter to bond stress capacity. Xue [9] performed load-reversed push-out tests on 32 circle CFST columns in 1997. Each test was loaded for 4 or 5 half-cycles. Based on the first loading cycle results, an elastic-plastic type of bond stress $(\tau)$ versus slip (S) curve was proposed. From 2006 to 2008, researchers at Xi' an University of Architecture \& Technology made a great effort to study the bond behavior of square and circular CFST columns [10-14]. Push-out tests on 9 circular specimens, 9 square specimens and 7 connections were carried out. The interface bond strength behavior was investigated and a different constitutive relationship, trilinear in nature, was proposed. The bond stress initially increases linearly with slip before reaching the peak point. After that, a short linear declining portion indicated that bond stress was decreasing with slip until the bond stress reached the residual bond strength. Finally, a simple horizontal portion represented the rigid slip between the steel and concrete.In BS5400 [15], a value of $0.4 \mathrm{MPa}$ is to be recommended as an ideal shear stress at the steel-concrete interface of concrete filled hollow steel sections. For these previous researchers have indeed attempted to develop an empirical equation for predicting bond strength from experimental results. Chang [4] proposed an empirical equation based on the effect of pre-stress due to the use of expansive cement and compressive strength, which is similar to an existing equation proposed by Cai [16]. In addition, a formula with five influencing factors (slenderness ratio, $\mathrm{D} / \mathrm{t}$ ratio, concrete strength, steel ratio, and constraining effect) was put forward by Kang [17].

Previous research has focused mainly on the bond in circular and square CFST columns. However, some evidence suggests that square CFST columns possess lower bond strengths than circular CFST columns in 2015, a total of 18 CFST specimens were tested to measure the bond strength between rectangular steel tubes and a concrete core by $\mathrm{Qu}$ [18]. The experimental study focused not only on the influence of factors such as concrete compressive strength, steel strength, interface length and cross-sectional proportions on the load-carrying capacity, but also assessed the adverse effect of lubrication at the steel-concrete interface. Lubricating the steel-concrete interface produced reductions in the bond strength between about $10 \%-50 \%$ of their values for equivalent specimens with no lubrication. This residual bond strength is attributed to microlocking.

\section{Interface bond strength and $\tau$-S constitutive models}

Considering all the test results from literature [18], the typical load-slip curve exhibits a number of important features; these are marked in Fig. 1 and listed in Table 1. For all specimens, designations starting with TCA refer to those which were lubricated (using butter) at the steel-concrete interface, whilst designations beginning with TCB had no lubrication. This is followed in the designation system with the specimen number-1 to 9. Initially linear behavior is observed up to the elastic limit load $\left(\mathrm{N}_{\mathrm{e}}\right)$, shown in Fig. 1 as point $\mathrm{A}$. This is followed by a nonlinear transitional part (AB). After reaching the ultimate push-out load $\mathrm{N}_{\mathrm{u}}$ at point $\mathrm{B}$, a rapidly declining portion $\mathrm{BC}$ appears down to a load $\mathrm{N}_{\mathrm{r}}$ before the relatively stable residual strength is reached. The test was stopped at point $\mathrm{E}$. After point $C$, although the load still varies with increasing slip, the average change is small and can be neglected. Most curves are of this type, especially those of Group TCB where no lubrication was used. Based on the analysis of the slip at point $\mathrm{C}$, it can be concluded that the average slip at point $\mathrm{C}$ is $2.82 \mathrm{~S}_{\mathrm{u}}$ for group TCA and $2.86 \mathrm{~S}_{\mathrm{u}}$ for Group TCB, respectively. According to this, it can be assumed that the load at point $\mathrm{D}$, where the slip is $3 \mathrm{~S}_{\mathrm{u}}$, can be considered as the residual push-out load. 


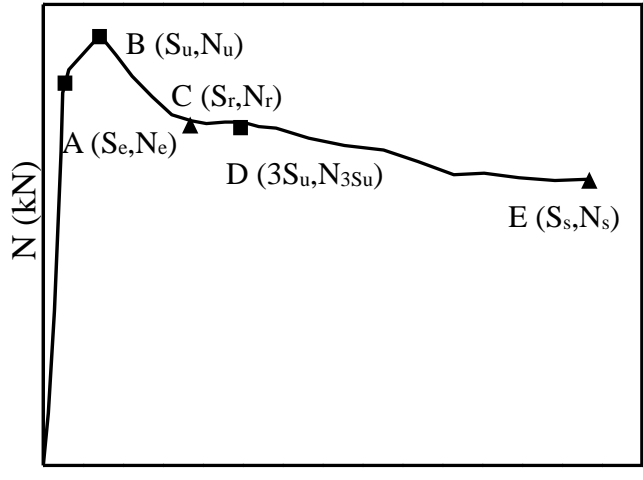

Slip (mm)

Fig. 1 Typical load-slip curve

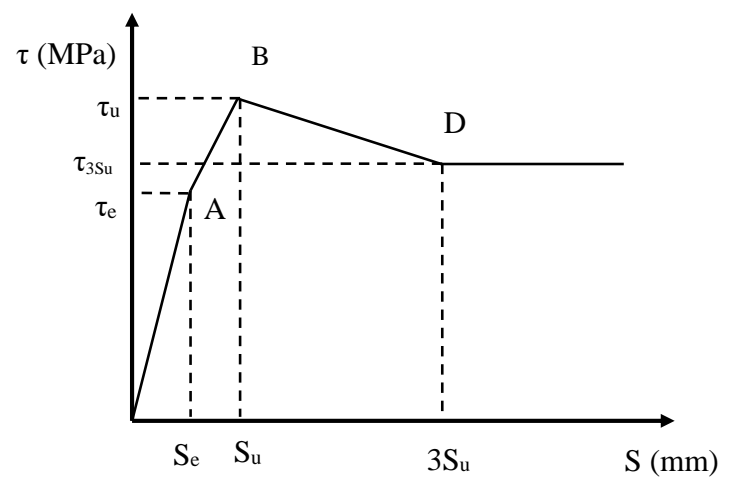

Fig. 2 A simplified four line $\tau-S$ 错误!未找到引用源。 constitutive model

Table 1 Summary of test results

\begin{tabular}{llllllllllllll}
\hline $\begin{array}{l}\text { Specimen } \\
\text { reference }\end{array}$ & $\begin{array}{l}\mathrm{S}_{\mathrm{e}} \\
(\mathrm{mm})\end{array}$ & $\begin{array}{l}\mathrm{N}_{\mathrm{e}} \\
(\mathrm{kN})\end{array}$ & $\begin{array}{l}\tau_{e} \\
(\mathrm{MPa})\end{array}$ & $\begin{array}{l}\mathrm{S}_{\mathrm{u}} \\
(\mathrm{mm})\end{array}$ & $\begin{array}{l}\mathrm{N}_{\mathrm{u}} \\
(\mathrm{kN})\end{array}$ & $\begin{array}{l}\tau_{u} \\
(\mathrm{MPa})\end{array}$ & $\begin{array}{l}\mathrm{S}_{\mathrm{r}} \\
(\mathrm{mm})\end{array}$ & $\begin{array}{l}\mathrm{N}_{\mathrm{r}} \\
(\mathrm{kN})\end{array}$ & $\begin{array}{l}3 \mathrm{~S}_{\mathrm{u}} \\
(\mathrm{mm})\end{array}$ & $\begin{array}{l}\mathrm{N}_{3 \mathrm{Su}} \\
(\mathrm{kN})\end{array}$ & $\begin{array}{l}\tau_{3 S_{u}} \\
(\mathrm{MPa})\end{array}$ & $\begin{array}{l}\mathrm{S}_{\mathrm{s}} \\
(\mathrm{mm})\end{array}$ & $\begin{array}{l}\mathrm{N}_{\mathrm{s}} \\
(\mathrm{kN})\end{array}$ \\
\hline TCA-1 & 1.22 & 4.46 & 0.016 & 4.39 & 7.89 & 0.028 & 11.6 & 5.53 & 13.2 & 6.43 & 0.014 & 40.7 & 3.82 \\
TCA-2 & 0.58 & 25.1 & 0.077 & 3.12 & 41.5 & 0.127 & 17.8 & 29.7 & 9.36 & 34.9 & 0.062 & 28.3 & 20.1 \\
TCA-3 & 0.29 & 8.10 & 0.022 & 4.32 & 25.0 & 0.067 & 18.4 & 21.6 & 12.9 & 21.3 & 0.050 & 19.8 & 18.8 \\
TCA-4 & 1.72 & 31.4 & 0.079 & 13.9 & 61.4 & 0.154 & 21.4 & 50.6 & 41.7 & 54.1 & 0.129 & 38.8 & 51.5 \\
TCA-5 & 1.54 & 21.8 & 0.047 & 4.35 & 38.7 & 0.083 & 9.70 & 33.4 & 13.1 & 33.6 & 0.083 & 41.3 & 38.7 \\
TCA-6 & 0.354 & 13.7 & 0.026 & 8.05 & 52.0 & 0.098 & 19.3 & 51.3 & 24.2 & 53.2 & 0.097 & 28.5 & 51.3 \\
TCA-7 & 0.041 & 20.5 & 0.031 & 10.8 & 38.8 & 0.058 & 33.9 & 18.0 & 32.5 & 8.54 & 0.021 & 44.7 & 13.9 \\
TCA-8 & 1.65 & 26.4 & 0.035 & 14.2 & 38.1 & 0.050 & 26.1 & 23.4 & 42.7 & 22.7 & 0.030 & 44.5 & 22.7 \\
TCA-9 & 0.212 & 22.7 & 0.026 & 12.7 & 52.0 & 0.061 & 20.6 & 37.3 & 38.1 & 37.3 & 0.043 & 25.5 & 37.3 \\
TCB-1 & 1.12 & 46.0 & 0.164 & 2.26 & 61.8 & 0.220 & 5.57 & 52.5 & 6.79 & 51.4 & 0.149 & 34.1 & 41.9 \\
TCB-2 & 1.09 & 56.7 & 0.173 & 1.33 & 75.1 & 0.229 & 3.78 & 66.1 & 3.98 & 65.8 & 0.229 & 37.4 & 75.1 \\
TCB-3 & 1.78 & 157 & 0.420 & 1.93 & 171 & 0.457 & 6.74 & 142 & 5.80 & 144 & 0.323 & 37.2 & 121 \\
TCB-4 & 1.89 & 168 & 0.422 & 1.94 & 178 & 0.445 & 3.39 & 116 & 5.83 & 113 & 0.282 & 49.5 & 113 \\
TCB-5 & 0.741 & 49.8 & 0.107 & 0.952 & 79.8 & 0.172 & 2.59 & 52.6 & 2.86 & 53.1 & 0.149 & 34.5 & 69.5 \\
TCB-6 & 1.37 & 106 & 0.316 & 2.42 & 170 & 0.320 & 2.95 & 138 & 7.25 & 137 & 0.279 & 17.8 & 148 \\
TCB-7 & 0.937 & 147 & 0.22 & 1.01 & 156 & 0.234 & 5.13 & 114 & 3.03 & 125 & 0.129 & 29.0 & 86.4 \\
TCB-8 & 1.05 & 270 & 0.354 & 2.24 & 290 & 0.379 & 5.66 & 209 & 6.71 & 210 & 0.260 & 39.5 & 198 \\
\hline & 0.266 & 88.6 & 0.103 & 3.52 & 132 & 0.154 & 12.8 & 154 & 10.5 & 147 & 0.171 & 18.0 & 147 \\
\hline
\end{tabular}

Generally, the average bond stress is adopted to represent interface bond strength. It is determined from:

$$
\tau=N / C L_{i}
$$

where $N=$ the push-out load value; $C=$ the perimeter of the concrete section in contact with the 
steel tube.

In this study three definitions of bond strength are used to investigate the bond behavior of the specimens. These are average elastic limit bond strength $\tau_{e}$, average ultimate bond strength $\tau_{u}$ and average post-peak residual bond strength $\tau_{3 S_{\mathrm{u}}}$, respectively. They are defined by:

$$
\begin{array}{cc}
\text { 错误!未找到引用源。 } & \tau_{e}=\frac{N_{e}}{(2(B-2 t)+2(D-2 t)) L_{i}} \\
\text { 错误!未找到引用源。 } & \tau_{u}=\frac{N_{u}}{(2(B-2 t)+2(D-2 t)) L_{i}} \\
\text { 错误!未找到引用源。 } & \tau_{3 S_{u}}=\frac{N_{3 S_{u}}}{(2(B-2 t)+2(D-2 t)) L_{i}}
\end{array}
$$

where $N_{e}$ is the elastic limit interface bearing capacity, which is shown in Fig. 1 as point $A, N_{u}$ is the ultimate interface bearing capacity, which is shown in Fig. 1 as point $B, N_{3 S u}$ is the post-peak residual interface bearing capacity, which is shown in Fig. 1 as point $\mathrm{D}\left(\mathrm{N}_{\mathrm{r}}=\mathrm{N}_{3 \mathrm{Su}}\right), \mathrm{B}$ is the length of the steel wide side, $\mathrm{D}$ is the length of the steel deep side, $\mathrm{t}$ is the thickness of the steel tube, and $\mathrm{Li}_{\mathrm{i}}$ is the length of the steel-concrete interface.

Using the test results, values of $\tau_{e}$, 错误!未找到引用源。and 错误!未找到引用源。 were calculated for each specimen; these are shown in Table 1. The average value of 错误!未找到引用 源。 for all specimens in the normal condition (Group TCA) was $0.29 \mathrm{MPa}$, while for the lubricated specimens (Group TCB), this value was $0.08 \mathrm{MPa}$. This clearly indicates that the lubrication has adverse effect on bond strength.

Interface bond strength can be considered as the combination of three different mechanisms: chemical adhesion, microlocking and macrolocking. The existence and magnitude of each mechanism changes as the relative slip between the concrete and the steel develops. Therefore, it is necessary to examine the bond strength versus slip curve to determine the development of each mechanism. As shown in literature [18], the common features of all the load-slip curves are an elastic stage and a transitional portion before the bond strength reached the peak point. The differences occur after the first peak point (ultimate bond stress).For the present tests, only TCB9 exhibited an increasing branch after the first peak point (Type3), whereas previous studies [1], have shown that most bond stress-slip curves exhibited this feature. This may be due to differences in the degree of irregularity of the steel inner surface influencing the development of the interface bond strength.

Based on the above analysis, a new four-part model is proposed, as shown in Fig. 2.The model utilizes key points from the measured curves (given in Table 1), connected by linear portions. It has an initial elastic portion until the bond stress reaches the elastic bond strength. Next, the transitional portion of the $\tau-S$ curve is represented with a second linear portion. After the bond stress reaches the first clear peak, the load decreases or increases linearly until the slip reaches a value of $3 \mathrm{~S}_{\mathrm{u}}$; the slope of this part is determined by the magnitudes of $N_{u}$ and 错误!未找到引用源。.Beyond this point, the relationship between 错误!未找到引用源。 and $S$ is such that the bond stress does not change with increasing slip. Comparisons between the simplified $\tau$-S constitutive model and the experimental $\tau$-S curves are shown in Fig. 3. The simplified model may be seen generally to provide a reasonable representation of the measured curves. 


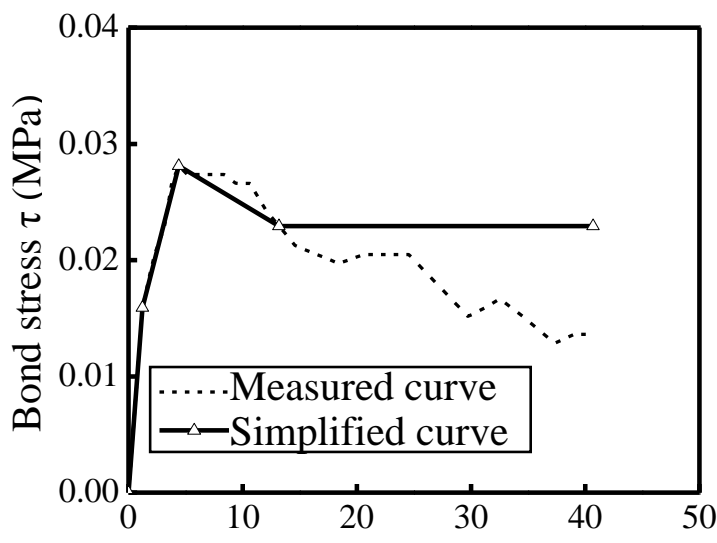

Slip (mm)

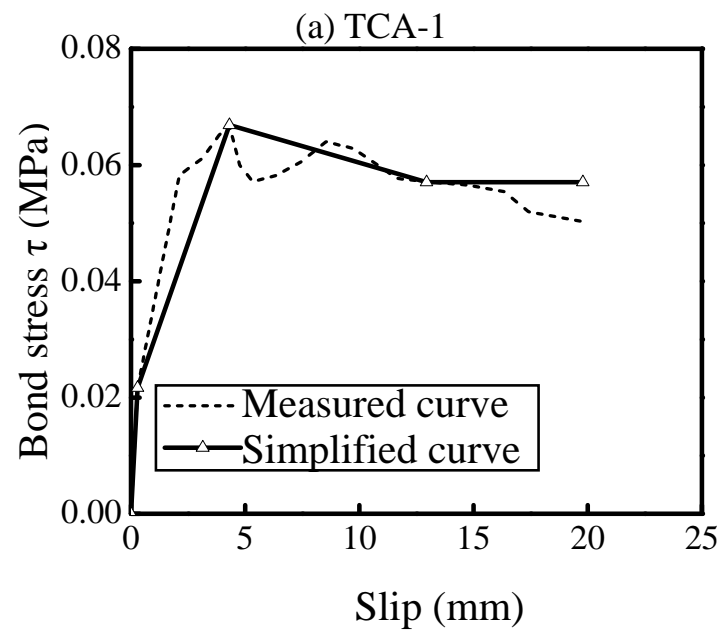

(c) TCA-3

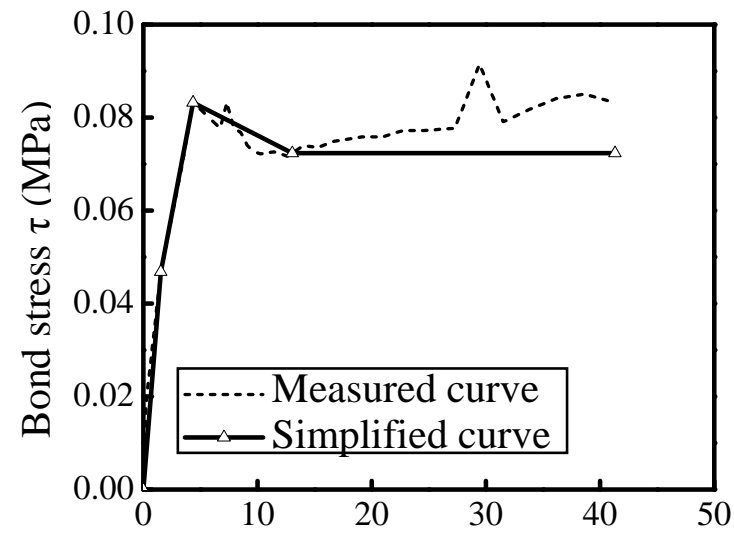

Slip (mm)

(e) TCA-5

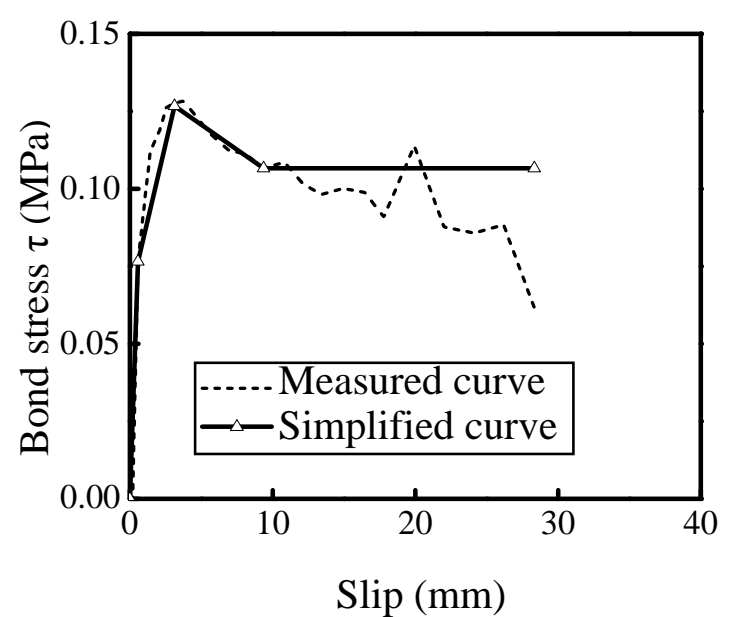

(b) TCA-2

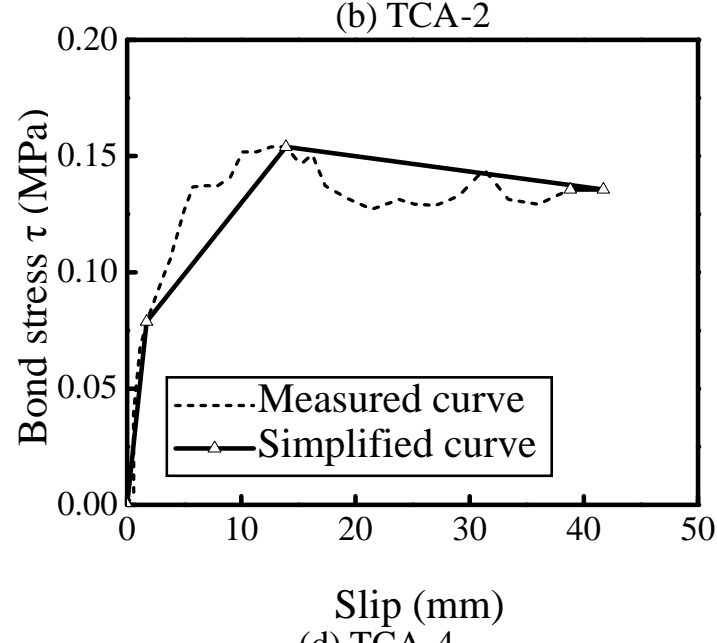

(d) TCA-4

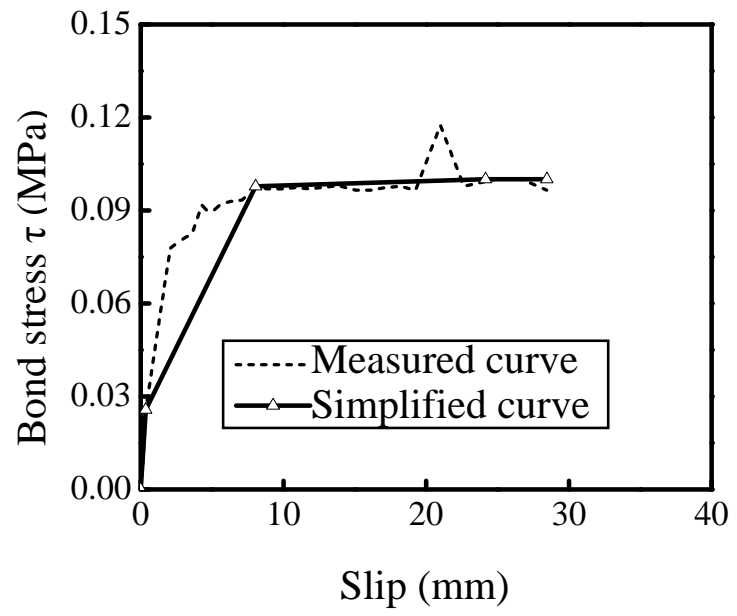

(f) TCA-6 


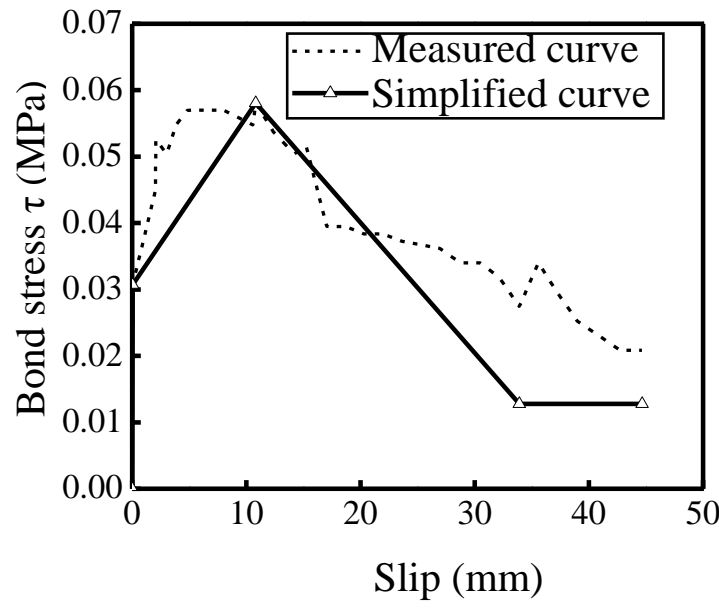

(g) TCA-7

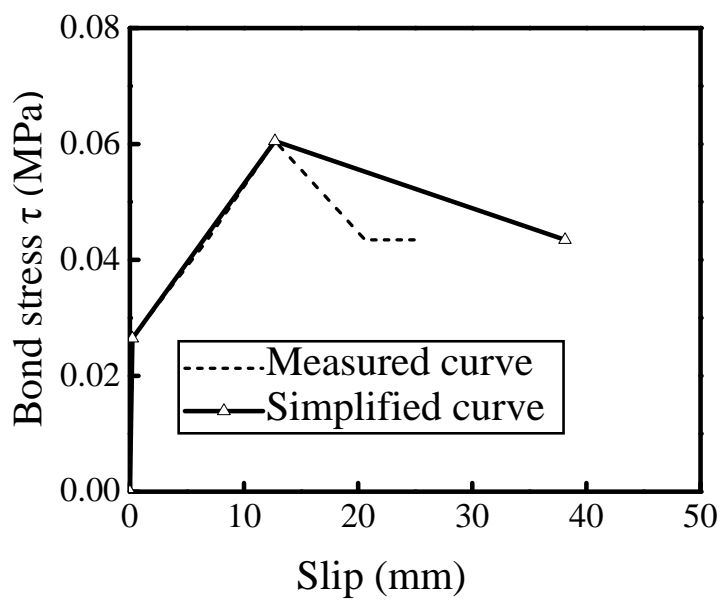

(i) TCA-9

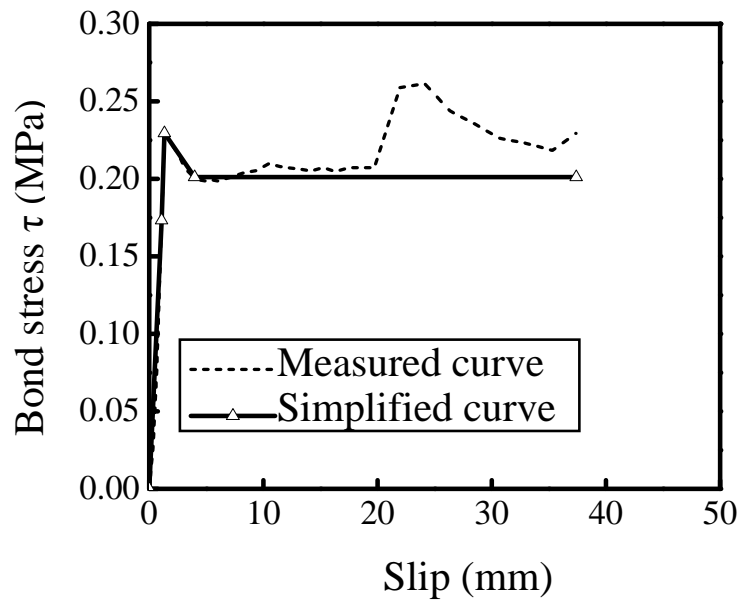

(k) TCB-2

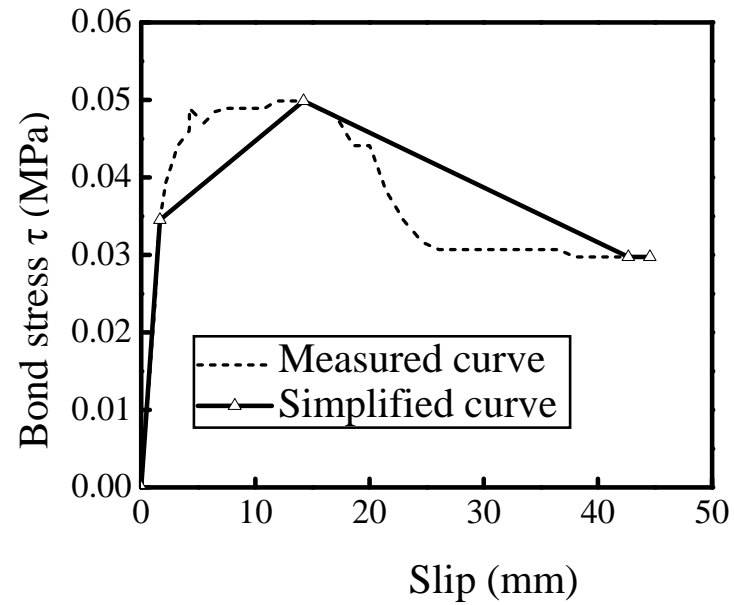

(h) TCA-8
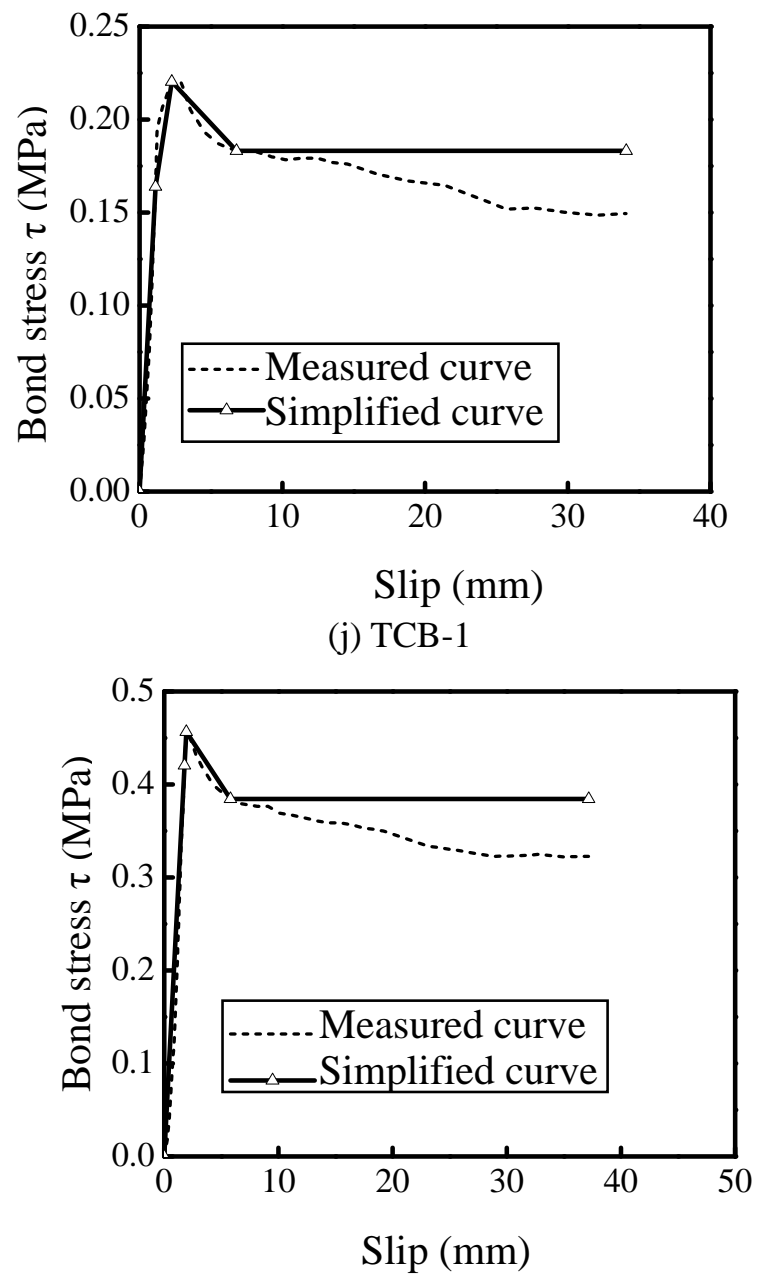

(l) TCB-3 


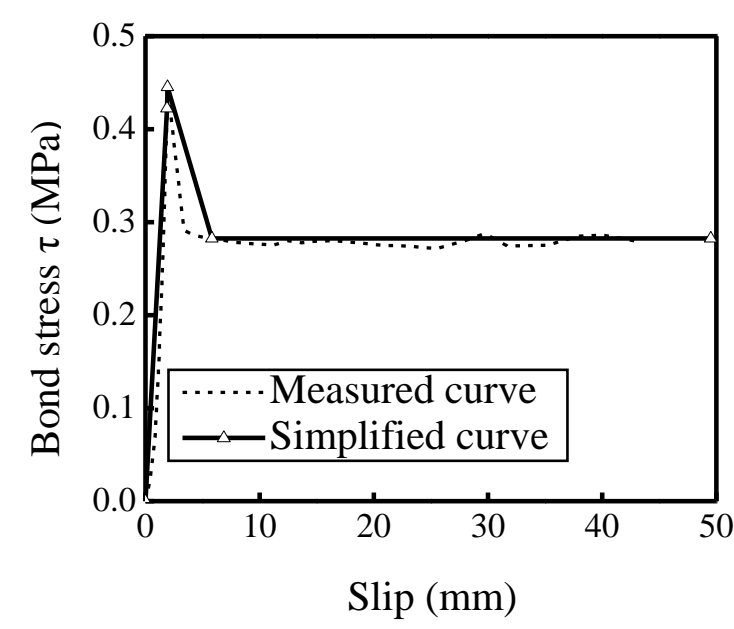

(m) TCB-4

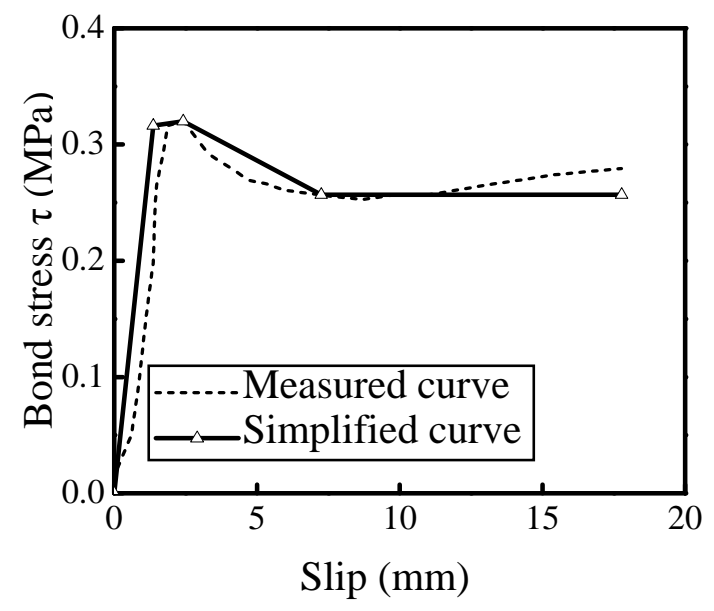

(o) TCB-6

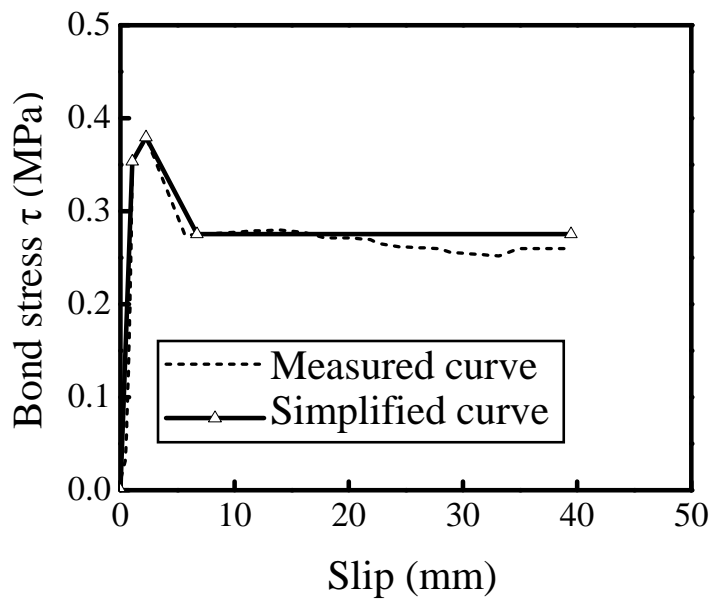

(q) TCB-8

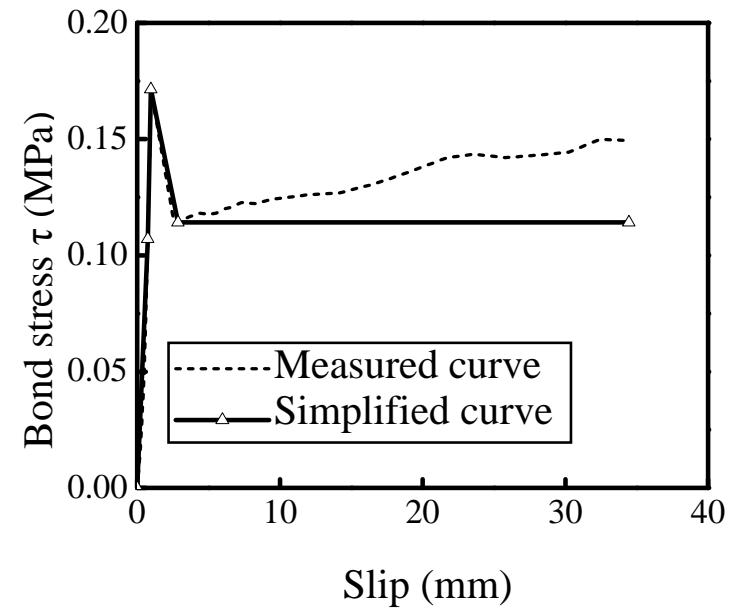

(n) TCB-5

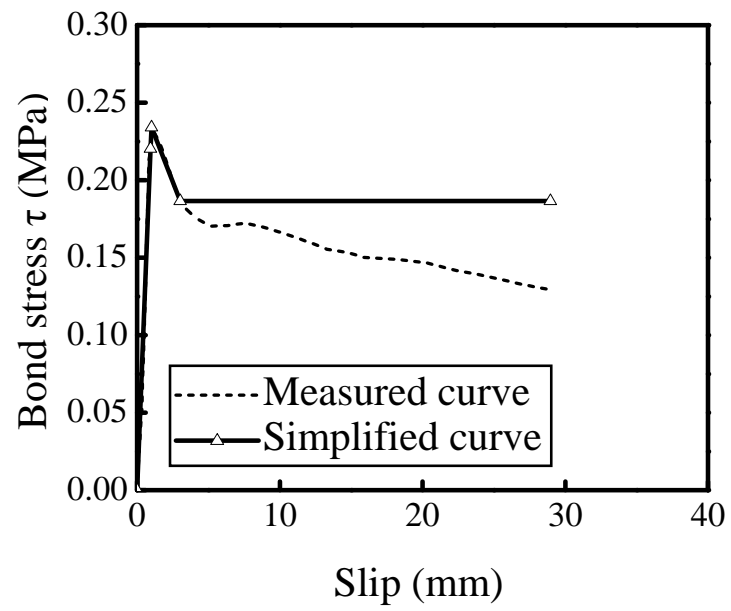

(p) TCB-7

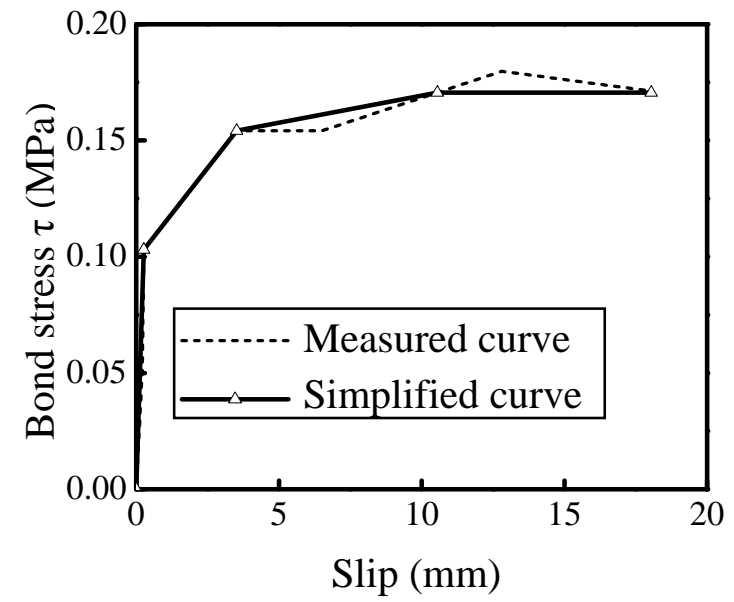

(r) TCB-9

Fig. 3 Comparison between the simplified model and the experimental $\tau$-s 错误!未找到引用源。curve

\section{Conclusion}

Previous research has focused mainly on the bond in circular and square CFST columns. However, some evidence suggests that square CFST columns possess lower bond strengths than circular CFST columns. In this paper, a series of previous push-out tests were citied to investigate the bond strength and $\tau$-S model for Rectangular CFST columns. Based on the previous laboratory testing 
results[18], three equations are designed to calculated are average elastic limit bond strength $\tau_{e}$, average ultimate bond strength $\tau_{u}$ and average post-peak residual bond strength $\tau_{3 S_{u}}$, respectively. Moreover, a new simplified four-part model has been proposed to describe the $\tau$-S response. The simplified model may be seen generally to provide a reasonable representation of the measured curves. Although the bond strength equations are given in this study, the calculated data is based on the measured data, it is necessary to do further research on the curve fitting prediction with only both geometrical parameters and material parameters of rectangular CFST columns.

\section{Acknowledgments}

This paper is supported by the National Natural Scientific Fund-Youth Science Fund Project" Research on Cooperativity and Composite Mechanical Performance for High-Performance Rectangular Concrete-filled Steel Tubular Columns" (51408026) and The Science and technology plan projects in general of Beijing municipal education commission- " The integration research of design and construction on low damaged precast concrete frame shear structure" (KM201610016005).

\section{References}

[1] K.S. Virdi, and P.J. Dowling: Bond strength in concrete filled circular steel tubes. Composite columns. CESLIC Report. CC11. Engineering structures laboratories, Civil Engineering Department. Imperial College, London. (1975).

[2] Z.H. Chen, X.S. Qu, X.D. Wang, R.R. Sun, and L.M. Li: Experimental study on the interface bearing capacity on boncrete-filled square steel tube. Journal of Harbin Institute of Technology. 41(2). 27-32 (2009).

[3] H. Shakir-Khalil: Resistance of concrete-filled steel tubes to pushout forces. The Structural Engineer. 71(13). 234-243 (1993b).

[4] X. Chang, C.K. Huang, D.C. Jing, and Y.C. Song: Push-out test of pre-stressing concrete filled circular steel tube columns by means of expansive cement. Construction and Building Materials. 23 (1). 491-497 (2009).

[5] H. Shakir-Khalil: Bond strength in concrete-filled steel hollow sections. Proceedings, International conference on steel and aluminum structures. Singapore. Vol. Composite steel structures. 157-168 (1993).

[6] H. Shakir-Khalil: Push-out strength of concrete-filled steel tubes to push out forces. The Structure Engineer. 71(13). 230-233 (1993a).

[7] H. Shakir-Khalil: Bond strength in concrete-filled steel hollow sections. Proceedings, International conference on steel and aluminum structures. Singapore. ICSAS 91. 22-24 (1991).

[8] C.W. Roeder, B. Cameron, and C.B. Brown: Composite action in concrete filled tubes. Journal of Structure Engineering. ASCE. 125 (5). 477-484 (1999).

[9] L.H. Xue, and S.H. Cai: Bond strength at the interface of concrete-filled steel tubular columns: part I. Building Science. 12(3). 22-28 (1996). [in Chinese].

[10] Y.Q. Liu: Study on the basic theory of bond-slip between steel tube and concrete in CFT structures and numerical simulation by ANSYS program. Xian University of Architecture and Technology, Xian. 39 (2006)

[11] C.Y. Huang: Experimental and Theoretical Study on the Bond Properties at the Interface of Concrete-Filled Square Steel Tubes.(2007)

[12] K. Hu: Study on the Bond-slip Constitutive Relations of Square Concrete-Filled Steel Tube.(2007)

[13] X.Y. Zhao: Experimental Research on Bond-slip Behavior between Steel and Concrete in Concrete Filled Square Steel Tube Structure.(2008) 
[14] X.L. Kang: Study on Compositing Mechanical Performance and Bond-Slip Performance of Concrete Filled Steel Tube.(2008)

[15] BS5400-5 (2005). Steel, concrete and composite bridges -Part 5: Code of practice for the design of composite bridges. British Standard Institution.

[16] S.H. Cai: Modern steel tube confined concrete structures. Beijing: China Communication Press. (2003)

[17] X.L. Kang: Study on compositing mechanical performance and bond-slip performance of concrete filled steel tube. Xian University of Architecture and Technology, Xian. 129-130 (2008)

[18] X.S. Qu, Z.H. Chen, D.A. Nethercot, L. Gardner, M. Theofanous: Push-out tests and bond strength of rectangular CFST columns. Steel and Composite Structures. Vol. 19(1). 21-41 (2015) 